TAS Journal, vol. 4, n. 4, p. 210 - 218

ISSN 2595-1521

DECEMBER 2020

caiquemovio@gmail.com

\title{
Comparison of function of passive modular exoskeletons for analysis of abduction movement and horizontal abduction of the upper limb
}

\author{
Fumagalli MA*, Pitta AJC*, Emanuel PCS*, Costa V* and Souza CMP§ \\ *Faculdade de Tecnologia Termomecanica, FTT, São Bernardo do Campo, Brasil . §Instituto \\ Federal de Educação, Ciência e Tecnologia de São Paulo, IFSP, São Paulo, Brasil..
}

\begin{abstract}
Stroke is one of the biggest problems of the health system in Brazil and in the world: not only due to high health costs, but also due to the treatment that does not guarantee a complete functional recovery. About $25 \%$ of the patients do not survive, and almost half of the survivors have a functional limitation of the upper and / or lower limbs. In the human body, the skeletal structure provides mechanical support for movements. On the shoulder, we find the greatest amount of degrees of articular freedom of the body - it allows arm movements in almost all directions, as well as in different angles. Compromising any of your movements directly affects autonomy in activities of daily living. The tracking of movements of the shoulder girdle and upper limbs accompanied by biomechanical assessments in the performance of activities of daily living provides support for rehabilitation. This measurement, however, is a complex activity due to the number of interdependent joints and movements. The objective of this research is to compare the readings performed on two passive exoskeletons, which measure threedimensionally the movement of the abduction / adduction and lateral abduction joints. To acquire the signals in the mechanical structure of the equipment, a reading system by a position sensor (encoder) is placed. The acquired signals are treated with a computational tool. The data are presented in real time, with visual feedback on joint movements. In the tests performed, the exoskeleton had no mechanical limitations that prevented the measurement of movements.
\end{abstract}

Keywords. Upper limb, Exoskeleton, Measurement system.

Introduction. Diseases and ills in the upper limb region may be the result of activities associated with ergonomic and labor issues, in addition to everyday movements. The growing concern with motor health, especially of the upper limbs, is due to aging, or rather, the longevity of society (1). The search for an autonomous life in old age depends largely on the movements of the shoulder and directly affects this point in ADL's, (activities of daily living).

The movement of the shoulder girdle and upper limbs, accompanied by biomechanical assessments in the performance of activities of daily living, provides support for rehabilitation. This measurement, however, is a complex activity due to the number of interdependent joints and movements (1). The vast majority of measurements of the upper limbs are derived from a 
simple method, such as the use of a mechanical goniometer (2). This technique makes it possible to check a joint only in one plane.

Rehabilitation robots have been exploited to train patients with impaired neural functions or to assist people with impaired limbs. The use of robotic therapies - associated with specific computer programs - allows an immediate perception of the results achieved and turns repetitive tasks into playful actions (2). This contributes to increase the motivation of patients undergoing these treatments and allows the possibility of measuring movements. Thus, monitoring the progress made in the different degrees of movement favors the development of new therapeutic and treatment approaches (2).

Within this conception, it is of interest to compare the functionality of two exoskeletons that accompany the mechanical structure of the upper limb segments, do not hinder the movements, measure the degrees of freedom three-dimensionally, and inform the patient and the therapist about the evolution of the rehabilitation (3).

Methodology. The system of this project is divided into two parts, which are: the passive exoskeleton system and the data acquisition circuit.

As for the exoskeletons, it is a "passive, mechanical, modular and anatomical exoskeleton capable of measuring three-dimensionally the degrees of freedom of the human upper limb in order to allow measurements to be performed during daily activities" (3). For better understanding, during this article the exoskeletons will be called E1 and E2.

The exoskeletons were based on a mathematical model proposed by Klopcar (4) which seeks to represent in a simplified way the kinematics of the scapular waist, arm and forearm system components, the models can be seen in Figure 1. 


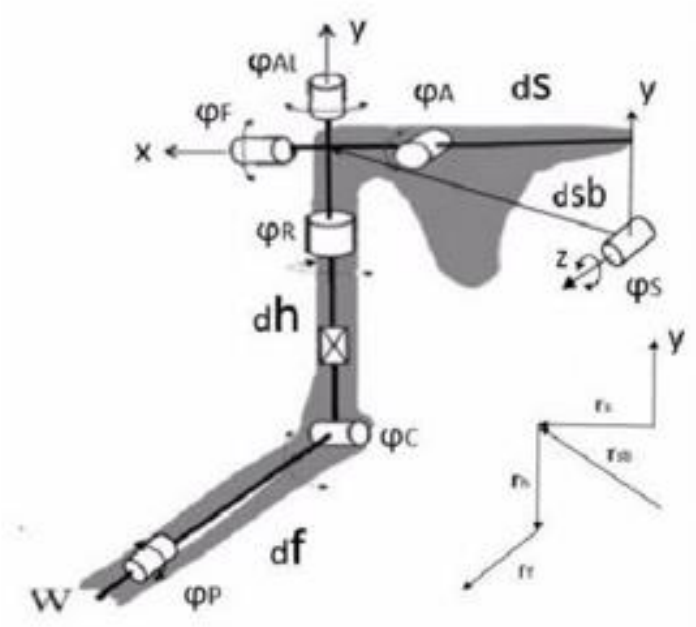

a)

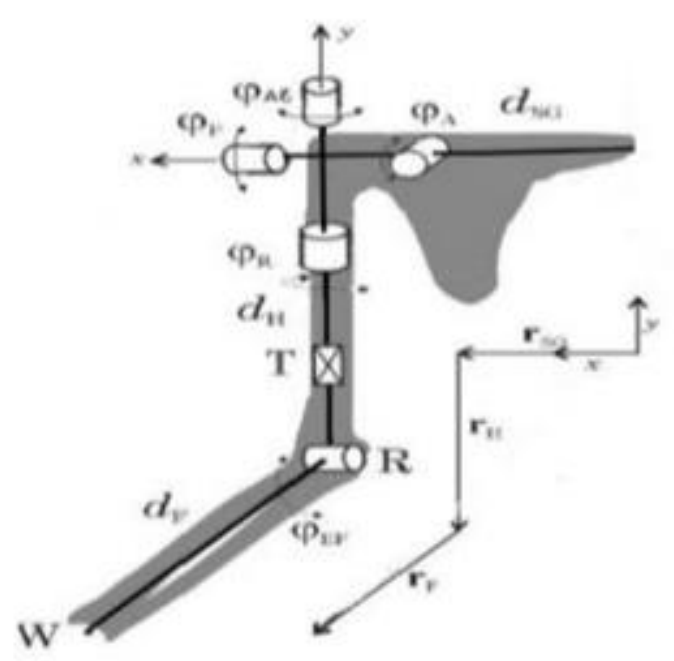

b)

Figure 1. Biomechanical models of the projects a) E1 and b) E2.

Based on the new biomechanical model, a table was constructed with the respective relationships between the angles of the model and the joints of the upper limb, as shown in Table 1.

Table 1. Biomechanical relations

\begin{tabular}{|c|c|c|}
\hline MODEL ANGLE & BIOMECHANICAL ROTATION & $\begin{array}{c}\text { AXIS OF } \\
\text { ROTATION }\end{array}$ \\
\hline$\varphi_{\mathrm{s}}$ & $\begin{array}{c}\text { SHOULDER LIFTING AND } \\
\text { DEPRESSION }\end{array}$ & $\mathrm{Z}$ \\
\hline$\varphi_{\mathrm{A}}$ & $\begin{array}{c}\text { ADDITION AND ABDUCTION OF } \\
\text { THE HUMBER }\end{array}$ & $\mathrm{Y}$ \\
\hline$\varphi_{\mathrm{AL}}$ & $\begin{array}{c}\text { HORIZONTAL ABDUCTION OF THE } \\
\text { HUMBER }\end{array}$ & $\mathrm{Y}$ \\
\hline$\varphi_{\mathrm{F}}$ & $\begin{array}{c}\text { FLEXION AND EXTENSION OF THE } \\
\text { HUMER }\end{array}$ & $\mathrm{X}$ \\
\hline$\varphi_{\mathrm{R}}$ & HUMBER ROTATION & $\mathrm{Y}$ \\
\hline
\end{tabular}




\begin{tabular}{|c|c|c|}
\hline$\varphi_{\mathrm{C}}$ & ELBOW FLEXION & $\mathrm{Z}$ \\
\hline$\varphi_{\mathrm{P}}$ & PRONATION AND SUPINATION & $\mathrm{Y}$ \\
\hline
\end{tabular}

In conjunction with the exoskeletons, a data acquisition system was created that uses microcontrollers and bluetooth to perform the readings of the encoders, convert the electrical pulses into numerical values and send them to the computer (via bluetooth connection), which in turn, will use this data to simulate the movement of the human upper limb in the supervisory (5).

When assembling the encoders are positioned on the axes, which will be measured with the Transistor-Logic (TTL) type terminal. This reading makes it possible to find the angular position and rotation of the axes. The supply voltage is connected to the input of the printed circuit board (6), shown in Figure 2.

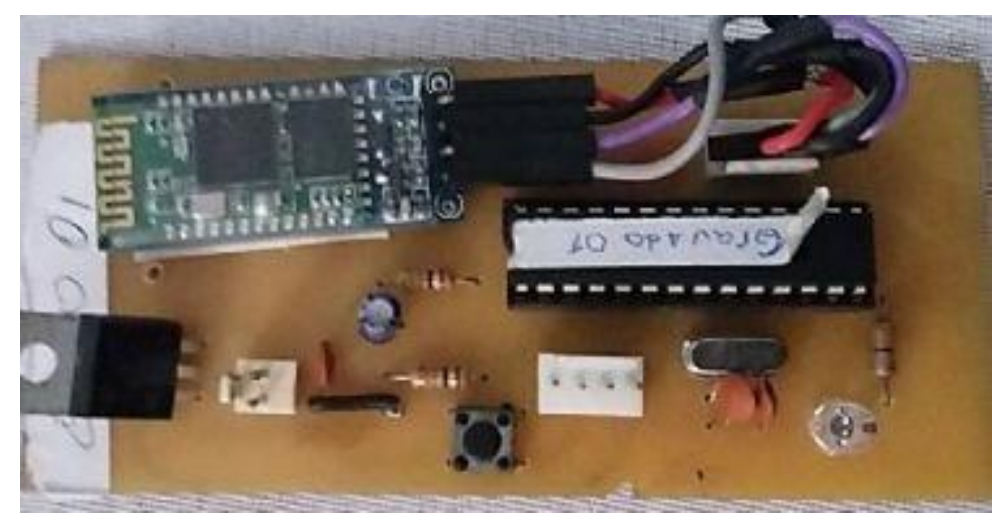

Figure 2. Printed circuit.

The circuit board contains microcontrollers model PIC 18F2431. This chip has a peripheral dedicated to the reading of the encoder: with this characteristic, it is possible to interpret the quadrature signals to acquire the position of the joints. The LabVIEW® software was used to monitor and supervise the data generated by the devices. Figure 3 shows the schematic sequence of the data processing flow signals. 
(a)
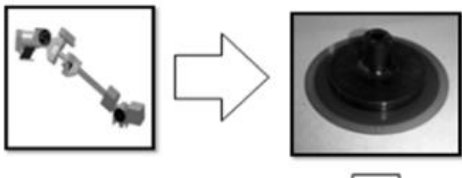

(b)

(d)

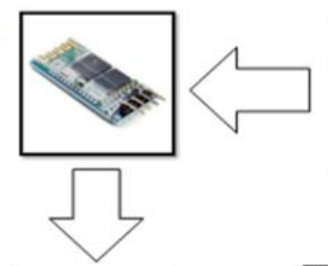

(e)

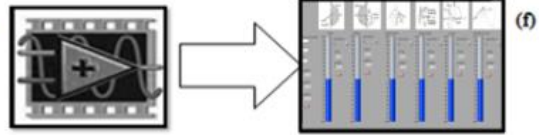

Figure 3. Flowchart of signal acquisition

The passive exoskeletons that were used in this project are shown in figure 4 - the exoskeleton E1 has encoders positioned on the movement axes that go from the shoulder girdle to the forearm, enabling the acquisition of data from up to seven movement axes. The encoder is read based on an encoded disk, formed by transparent radial windows, the infrared light beam illuminates the encoded disk when the images of the transparent windows are projected on the receiver, the receiver converts the light into electrical pulses, electrical pulses are converted into binary numbers and analyzed by a program that will convert the information into speed, acceleration rate, distance, rotation, position or direction (7). The exoskeleton E2, on the other hand, has encoders positioned on the movement axes only in the shoulder region, enabling data acquisition in up to six movement axes. 


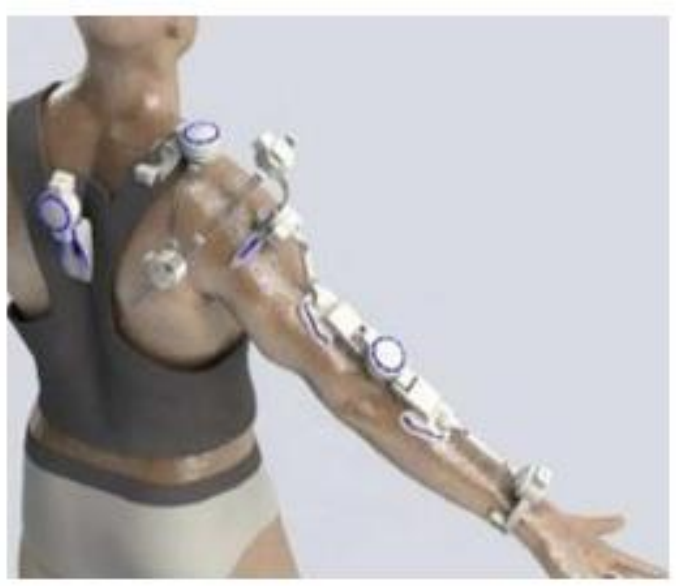

a)

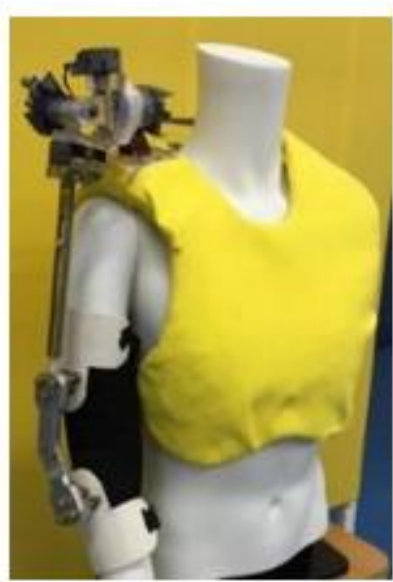

b)

Figure 4. Exoskeletons a) E1 and b) E2.

To carry out the calibration of the exoskeletons, a sequence of tests was performed. In this step, the device was worn on the research authors and then connected to an instrumentation plate, making measurements and comparing with the goniometer. The calibration of each of the joints of the device was performed with the aid of an analog goniometer.

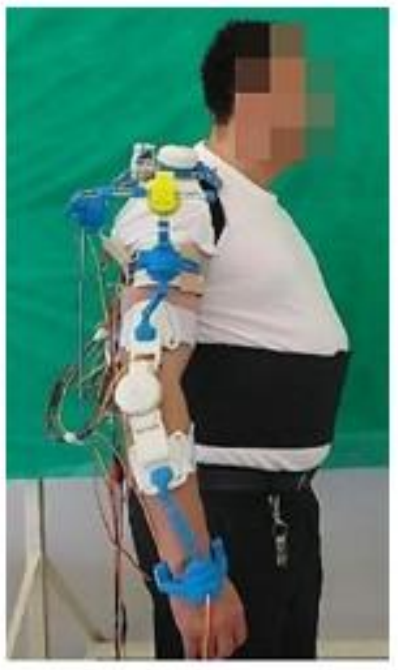

a)

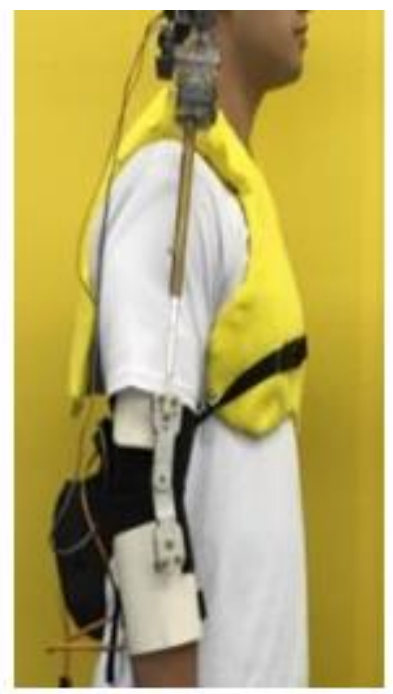

b) 
Figure 5. Devices positioned on the human body.

Results. To perform the tests, the devices were placed on the human body as shown in Figure 5.

In carrying out the behavior of the device in a dynamic action, series of tests were performed with repetitive movements in order to raise the mechanical limits of the exoskeleton, as well as asking the participants to perform the orthostatic posture and the neutral position for 5 seconds and then return to neutral position. This methodology was adopted for both movements: abduction and horizontal abduction.

In exoskeleton E1, all the data resulting from these tests were stored in a file in .txt format for the construction of graphs for each of the joints. In exoskeleton E2, data were shown through the supervisory.

In the readings of the horizontal abduction movement, shown in figure 6 , the readings were made reliably of the movement, since, with the arm stopped, there was no change in the reading value.

In the exoskeleton E1, the maximum value of $86.28^{\circ}$ was obtained, while in the exoskeleton E2 the maximum value was reached within the mechanical limitations. The value obtained was $74^{\circ}$ in the LabVIEW supervisory.

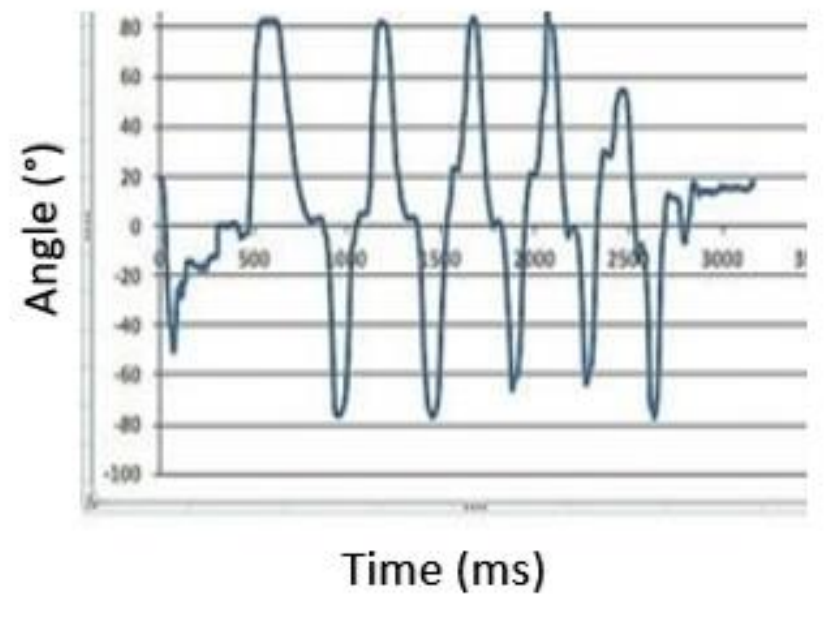

a)

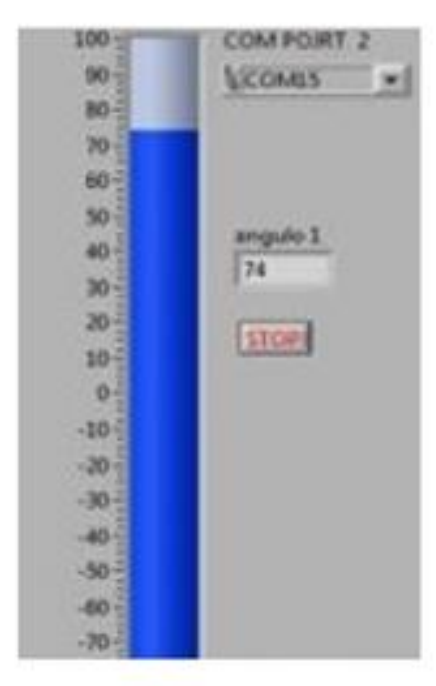

b)

Figure 6. Horizontal Abduction Movement

When reading the abduction movement, shown in figure 7 , the same parameters were used, and the tests performed, the exoskeleton E1 presented the value of $100^{\circ}$ while the exoskeleton E2 
presented the value of $31^{\circ}$, as it is necessary to consider the value of the axillary midline, participant was $25^{\circ}$, the total value obtained in the reading was $56^{\circ}$.

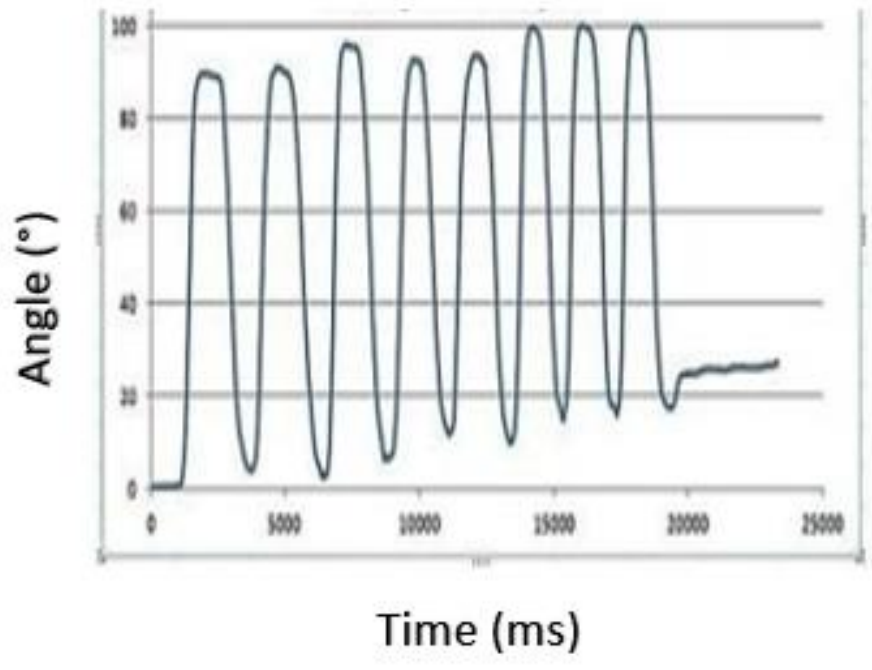

a)

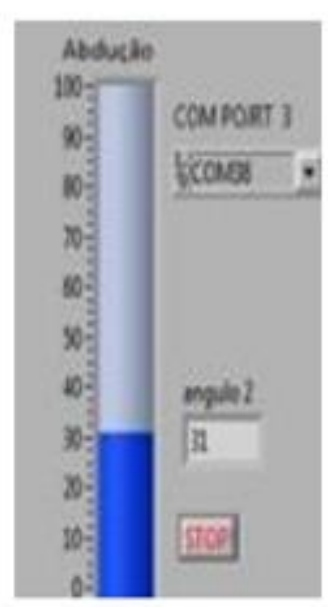

b)

Figure 7. Abduction Movement

These differences in readings are due to the fact that the E2 exoskeleton has mechanical limitations while the E1 exoskeleton is more modular to the human body.

Conclusion. As proposed in this work: the development of a mechanical device for tracking shoulder and elbow movements, which is important for functional, ergonomic investigations and in assessments of Daily Living Activities (ADLs).

The measurements performed showed positive results in the collection of positioning data for two movements: those of abduction / adduction and lateral abduction successfully. A system for acquiring the signals of the angular movements of the device used was developed by another work and this system was able to promote the acquisition of data from the two encoders. With LabVIEW®, two supervisors were generated, where the results generated by the joint movement are presented - and these helped in the comparison and validation of the position of the motion encoders when compared with the goniometer data.

In tests performed with movements of activities of daily living, the exoskeletons behaved satisfactorily within the limitations that could originate, for example, in some non-anatomical condition of the devices. The difference between the two devices became clear during the tests, as the E1 exoskeleton was developed in a more anatomical way and modeled on the body than 
the E2 exoskeleton, in addition to reducing the weight of the constituent parts and adapting the equipment connections to anatomical conditions of the human body.

Acknowledgments. We thank the Faculdade de Tecnologia Termomecânica for the support given during the project, and Caique Movio thanks CAPES.

Disclosure. The authors report no conflicts of interest in this work.

\section{References.}

(1) Engin, AE.; Tumer, ST. Three-Dimensional Kinematic Modelling of the Human Shoulder Complex - II. Mathematical Modelling and Solution via Optimization, Journal of Biomechanical Engineering, 111, 113-121. 1989.

(2) Marques, AP. Ângulos articulares dos membros superiores: manual de goniometria. 2 ed. São Paulo: Editora Manole. 2003.

(3) Emanuel, PCS. Dispositivo de um exoesqueleto modular passivo para medição de movimentos do membro superior e avaliação das atividades da vida diária. Universidade de Mogi das cruzes. Mogi das cruzes, p. 77. 2015.

(4) Klopcar, N.; Tomsic, M.; Lenarcic, J.A kinematic model of the shoulder complex to evaluate the arm-reachable workspace. Journal of Biomechanics.40, 86-91, 2007.

(5) Costa, VL. ; Emanuel, PCDS . Reprodução dos movimentos do membro superior humano em ambiente virtual. In: CONIC - Congresso Nacional de Iniciação Científica, Guarulhos SP, 2016.

(6) Souza, CMP.; Fumagalli, M. A.; Emanuel, PCS.; Gomes, SCP.; Costa,V. Dispositivo de aquisição do movimento para membro superior. Revista Caleidoscópio, v.1. p.45-60,2015.

(7) Costa, V. Dispositivo para medição dos movimentos cinemáticos do membro superior. Universidade de Mogi das cruzes. Mogi das cruzes, p. 94. 2015. 